\title{
Splenectomy for refractory Evans' syndrome associated with antiphospholipid antibodies: report of two cases
}

Josep Font, Sònia Jiménez, Ricard Cervera, Mario García-Carrasco, Manuel Ramos-Casals, Jaume Campdelacreu, Miguel Ingelmo

\begin{abstract}
The main haematological manifestations seen in patients with antiphospholipid antibodies (aPL) are thrombocytopenia, usually mild, and haemolytic anaemia with a positive Coombs test. Owing to the shared characteristics with idiopathic thrombocytopenic purpura, similar rules are followed in the treatment of these cytopenias. Two patients with severe aPL associated cytopenias, who required splenectomy after being refractory to steroids, immunosuppressive agents, and other treatments (intravenous gammaglobulin, danazol), are described, and previously reported cases are reviewed. (Ann Rheum Dis 2000;59:920-923)
\end{abstract}

The antiphospholipid syndrome (APS) is characterised by arterial/venous thrombosis, recurrent pregnancy loss, or thrombocytopenia in the presence of antiphospholipid antibodies (aPL). ${ }^{1}$ These antibodies are identified as lupus anticoagulant, which prolongs phospholipid dependent coagulation tests, or as anticardiolipin antibodies (aCL) detected by immunoassays. This entity, first described by Hughes in 1983 in patients with systemic lupus erythematosus (SLE), ${ }^{2}$ may appear in patients with no underlying disease - the "primary" APS. ${ }^{3}$

There are well documented associations between aPL and abnormalities of specific cellular components of the blood, such as thrombocytopenia, haemolytic anaemia, and, less commonly, leucopenia. ${ }^{4}$ Thrombocytopenia is usually mild and benign $\left(70-120 \times 10^{9} / 1\right)$, rarely associated with bleeding complications, and, generally, does not require treatment. Moreover, some authors have shown that haemolytic anaemia and Coombs positivity is also associated with aPL, ${ }^{4}$ and in some patients with primary APS, both thrombocytopenia and haemolytic anaemia may occur together.

We describe two patients with severe aPL associated cytopenias (haemolytic anaemia and thrombocytopenia) who required splenectomy after being refractory to steroids and immunosuppressive treatment, and review cases previously reported.

\section{Case reports}

CASE 1

A 49 year old woman was admitted to our hospital in August 1987 with cutaneous purpura on the legs and spontaneous mouth bleeding. There was no previous history of thrombotic events or obstetric complications. Laboratory measurements showed a platelet count below $10 \times 10^{9} / 1$ and a normochromic anaemia (haemoglobin $100 \mathrm{~g} / \mathrm{l}$ ) with a positive Coombs test and a raised reticulocyte count. An immunological profile showed negative antinuclear antibodies. A bone marrow biopsy showed normal cellularity with an increased megakaryocyte count. The patient was diagnosed as having Evans' syndrome, and treatment with prednisone (1 $\mathrm{mg} / \mathrm{kg} / \mathrm{d}$ ) was started with an initial increase in the haematological values. In May 1992 the patient presented an acute respiratory infection, and the platelet count began to fall below $50 \times 10^{9} / 1$ and the haemoglobin value under 80 $\mathrm{g} / \mathrm{l}$. High positive $(+++)$ aCL of the $\operatorname{IgM}$ isotype were detected, and lupus anticoagulant was absent. Subsequently, the patient required several readmissions, most due to gastrointestinal or respiratory infections, with a coincidental severe decrease of the haemoglobin value and platelet count, and IgM aCL remained positive at high titre $(+++)$. During this time the patient received different treatments with high doses of steroids, immunosuppressive treatments (oral cyclophosphamide $50 \mathrm{mg} / \mathrm{d}$, azathioprine $100 \mathrm{mg} / \mathrm{d}$ ), and danazol, without response. In April 1995 the first dose of intravenous gammaglobulin was given. A total of five doses were given until June 1997, without response. Finally, splenectomy was performed in January 1998, with previous prophylactic antibiotics and vaccination, without postoperative complications. After splenectomy, the haemoglobin stabilised above $120 \mathrm{~g} / \mathrm{l}$ and the platelet count above $500 \times 10^{9} / 1$. Two years later, the patient is doing well without haemorrhagic manifestations and with a normal haemoglobin value and platelet count (fig 1).

CASE 2

The patient, a 32 year old woman, was admitted to our hospital because of haemolytic anaemia and thrombocytopenia that could not be controlled with drugs. When she was 30 the patient had presented polyarthralgias and spontaneous smouth bleeding. The laboratory variables showed leucopenia $\left(2 \times 10^{9} / 1\right)$, normochromic anaemia (haemoglobin $90 \mathrm{~g} / \mathrm{l}$ ) with a positive Coombs test and a platelet count of $15 \times 10^{9} / 1$. An immunological profile showed positive antinuclear antibodies (at a titre of 1/320), hypocomplementaemia (C4 levels below 0.07) and positive IgG and IgM aCL at high titre $(+++)$. Anti-dsDNA and antibodies to extractable nuclear antigens were negative. The patient was diagnosed as having a 




Figure 1 Summary of the clinical and therapeutic course of patient 1. Ig = intravenous gammaglobulin; Aza = azathioprine.

lupus-like syndrome, and treatment with prednisone $(1 \mathrm{mg} / \mathrm{kg} / \mathrm{d})$ was started, with an initial increase in the haematological values. Subsequently, she developed several complications related to corticosteroid treatment-namely, diabetes mellitus, Cushing's syndrome, and osteoporosis-and the haematological values began to fall. Treatment with immunosuppressive drugs (oral cyclophosphamide and azathioprine), danazol, and intravenous gamma- globulin was also added, without response. Finally, splenectomy was performed in December 1998 and, one year later the patient has a normal haemoglobin value and platelet count without treatment.

\section{Discussion}

The main haematological manifestations seen in patients with aPL are thrombocytopenia and haemolytic anaemia. The co-occurrence of

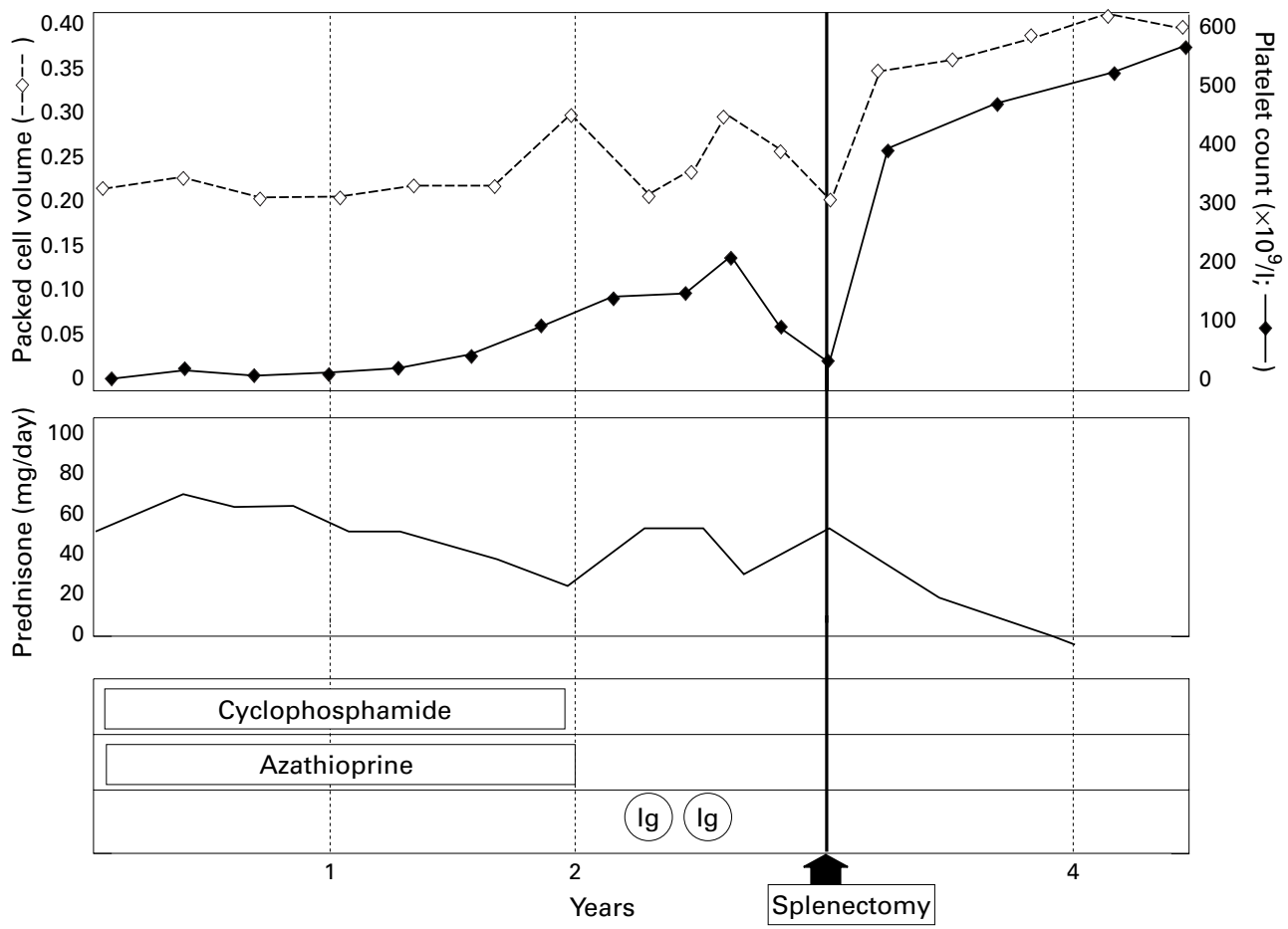

Figure 2 Summary of the clinical and therapeutic course of patient 2. Ig = intravenous gammaglobulin. 
Table 1 Splenectomy in patients with refractory aPL associated cytopenias: reported cases

\begin{tabular}{|c|c|c|c|c|c|c|c|}
\hline Case & Author (date) & Diagnosis & $a P L$ & Age/sex & Cytopenia & Outcome & $\begin{array}{l}\text { Current } \\
\text { treatment }\end{array}$ \\
\hline 1 & Ballerini et al $(1995)^{18}$ & PAPS & IgG & $23 / \mathrm{F}$ & Thromb & CR & - \\
\hline 2 & Leuzzi et al $(1997)^{17}$ & PAPS & IgG, IgM & $35 / \mathrm{F}$ & Thromb & $\mathrm{CR}$ & - \\
\hline 3 & Leuzzi et al $(1997)^{17}$ & PAPS & IgG, IgM & $33 / \mathrm{F}$ & Thromb & $\mathrm{CR}$ & - \\
\hline 4 & Hakim et al $(1998)^{19}$ & PAPS & IgG & $39 / \mathrm{F}$ & Thromb & $\mathrm{CR}$ & - \\
\hline 5 & Hakim et al $(1998)^{19}$ & PAPS & IgG & $23 / \mathrm{F}$ & Thromb & $\mathrm{CR}$ & - \\
\hline 6 & Hakim et al $(1998)^{19}$ & PAPS & IgG & $40 / \mathrm{F}$ & Thromb & $\mathrm{CR}$ & - \\
\hline 7 & Hakim et al $(1998)^{19}$ & SLE & IgG & $37 / \mathrm{F}$ & Thromb & $\mathrm{CR}$ & Pred, HCQ \\
\hline 8 & Hakim et al $(1998)^{19}$ & SLE & IgG & $28 / \mathrm{F}$ & Thromb & $\mathrm{CR}$ & Pred, MTX \\
\hline 9 & Hakim et al $(1998)^{19}$ & SLE & IgG & $40 / \mathrm{F}$ & Thromb & $\mathrm{CR}$ & Pred, AZA \\
\hline 10 & Galindo et al (1999) ${ }^{20}$ & SLE & $\operatorname{IgM}$ & $30 / \mathrm{F}$ & Thromb & $\mathrm{CR}$ & Pred, HCQ \\
\hline 11 & Galindo et al (1999) ${ }^{20}$ & SLE & LA & $41 / \mathrm{F}$ & Thromb & $\mathrm{CR}$ & Pred, HCQ \\
\hline 12 & Galindo et al (1999) ${ }^{20}$ & SLE & LA, IgG & $25 / \mathrm{F}$ & Thromb & $\mathrm{CR}$ & Pred, HCQ \\
\hline 13 & Galindo et al (1999) ${ }^{20}$ & SLE & LA, IgG, IgM & $36 / \mathrm{F}$ & Thromb & $\mathrm{CR}$ & Pred, AZA \\
\hline 14 & Galindo et al (1999) ${ }^{20}$ & SLE & LA & $58 / \mathrm{F}$ & Thromb & $\mathrm{CR}$ & Pred \\
\hline 15 & Galindo et al (1999) ${ }^{20}$ & PAPS & LA, IgG, IgM & $35 / \mathrm{F}$ & Thromb, HA & $\mathrm{CR}$ & Pred \\
\hline 16 & Galindo et al (1999) ${ }^{20}$ & SLE & IgG & $47 / \mathrm{F}$ & Thromb & $\mathrm{CR}$ & HCQ \\
\hline 17 & Galindo et al (1999) ${ }^{20}$ & SLE & IgG, IgM & $22 / \mathrm{F}$ & Thromb & $\mathrm{CR}$ & Pred, CQ \\
\hline 18 & Galindo et al (1999) ${ }^{20}$ & SLE & LA, IgG, IgM & $36 / \mathrm{F}$ & Thromb, HA & $\mathrm{CR}$ & Pred \\
\hline 19 & Galindo et al (1999) ${ }^{20}$ & PAPS & LA & $47 / \mathrm{M}$ & Thromb & $P R$ & Pred \\
\hline 20 & Galindo et al $(1998)^{20}$ & SLE & LA, IgG & $52 / \mathrm{F}$ & Thromb & PR & HCQ \\
\hline 21 & Present study & PAPS & $\operatorname{IgM}$ & $60 / \mathrm{F}$ & Thromb, HA & $\mathrm{CR}$ & - \\
\hline 22 & Present study & LLD & IgG, IgM & $32 / \mathrm{F}$ & Thromb, HA & $\mathrm{CR}$ & - \\
\hline
\end{tabular}

aPL = antiphospholipid antibodies; PAPS = primary antiphospholipid syndrome; SLE = systemic lupus erythematosus; LLD = lupus-like disease $\mathrm{LA}=$ lupus anticoagulant $\mathrm{F}=$ female $\mathrm{M}=$ male; Thromb = thrombocytopenia $\mathrm{HA}=$ haemolytic anaemia $\mathrm{CR}$ $=$ complete remission; $\mathrm{PR}=$ partial remission; Pred = prednisone; $\mathrm{HCQ}=$ hydroxychloroquine; $\mathrm{MTX}=$ methotrexate; $\mathrm{AZA}=$ azathioprine; $\mathrm{CQ}=$ chloroquine.

both immune mediated cytopenias was originally described by Evans in $1949 .^{5}$ This strong association of thrombocytopenia and haemolytic anaemia suggests the possibility of a common mechanism of increased cellular destruction. Antibodies are thought to bind to the surface of the platelets and erythrocytes and fix complement, and the resulting cellular immune complex is destroyed by the fixed macrophages of the reticuloendothelial system. There has been increasing interest in recent years in the precise nature of the antigenic targets to which aPL bind platelets or erythrocytes, or both. ${ }^{6-8}$

Thrombocytopenia appears in about one third of the patients with aPL. Cuadrado et al reported a prevalence of $23 \%$ in a series of 171 patients with APS, being severe $\left(<50 \times 10^{9} / 1\right)$ only in six of them $(18 \%) .{ }^{9}$ Rarely, this disorder requires treatment and, owing to shared characteristics with idiopathic thrombocytopenic purpura, similar treatment could be followed-that is, high dose corticosteroids, immunosuppressive or immunomodulating agents, and intravenous immunoglobulin treatment. When steroids or immunosuppressive agents are unsuccessful, splenectomy is usually performed to remove the major site of platelet destruction and antibody production. There is improvement in $70-90 \%$ of patients after splenectomy, and platelets are permanently restored to normal levels in at least two thirds of patients. ${ }^{10}$ Unfortunately, there are no clinical or analytical variables that adequately predict the response to splenectomy. Only the intensity of bleeding, age, and the immediate postoperative peak platelet count are weak predictors of outcome. ${ }^{11}$

Some authors have analysed the relation between the isotype of aCL and haemocytopenias and found a significant association between IgM aCL and haemolytic anaemia. ${ }^{12-14}$ Furthermore, a prospective study showed that the presence of IgM aCL is associated with the development of haemolytic anaemia in patients with SLE. ${ }^{15}$ Recommendations for the management of immune mediated haemolytic anaemia associated with high titre aPL are similar to those for immune mediated thrombocytopenia. $^{4}$

Previous experience of the value of splenectomy in the treatment of aPL associated cytopenias is limited (table 1)..$^{16-21}$ In 1995 Ballerini et al described the first case, a patient with primary APS and severe thrombocytopenia treated unsuccessfully with steroids, who was finally treated with splenectomy, with a sustained and complete remission. ${ }^{18}$ More recently, two studies have focused on the response to splenectomy in patients with APS and refractory thrombocytopenia. Hakim et al reviewed the outcome of splenectomy in 12 patients with severe thrombocytopenia, three of them with primary APS. ${ }^{19}$ After splenectomy, complete remission of the thrombocytopenia occurred. There were no complications from the splenectomy, and the patients who received this treatment within one year of diagnosis of thrombocytopenia seemed to respond well. In another recent study Galindo et al analysed 55 patients with APS with thrombocytopenia $\left(<100 \times 10^{9} / 1\right)$ and reported that splenectomy was required in $11(20 \%)$ patients, nine with an APS associated with SLE and the other two with a primary APS. ${ }^{20}$ Postoperative complications were not reported in any patient, and all but two were responsive to splenectomy. The results obtained in the patients published, including our patients, support the usefulness of splenectomy in the treatment of refractory cytopenias associated with aPL, with a high rate of response after the follow up and no postoperative complications.

In conclusion, patients with aPL related haemocytopenias (thrombocytopenia or haemolytic anaemia, or both) often gain long term remission of refractory cytopenias after splenectomy, without exacerbation of their primary disease. Modern surgical techniques and the use of prophylactic antibiotics and vaccina- 
tion have made splenectomy a safer option in patients who do not respond to classic treatments, such as corticosteroids.

1 Font J, Lopez-Soto A, Cervera R, Balasch J, Pallarés L, Navarro M, et al. The primary antiphospholipid syndrome: antiphospholipid antibody pattern and clinical features of a series of 23 patients. Autoimmunity 1991;9:69-75.

2 Hughes GRV. Thrombosis, abortion, cerebral disease and the lupus anticoagulant. BMJ 1983;287:1088-9.

3 Asherson RA, Khamashta MA, Ordi-Ros J, Derksen RH, Machin SJ, Barquinero J, et al. The "primary" antiphospholipid syndrome: major clinical and serological features. pholipid syndrome: major clinical and sero

4 Davies KA, Athanassiou P, Loizou SA. Thrombocytopenia and other haematological abnormalities in the antiphospholipid syndrome. In: Asherson RA, Cervera R, Piette JC, pholipid syndrome. In: Asherson RA, Cer syndrome. Boca Shoenfeld Y, eds. The antiphospholipid

5 Evans RS, Duane RT. Acquired hemolytic anemia. Blood 1949;4:1196.

6 Khamashta MA, Harris EN, Gharavi AE, Derue G, Gil A Vazquez JJ, et al. Immune mediated mechanism for thrombosis: antiphospholipid antibodies binding to platelet membranes. Ann Rheum Dis 1988;47:849-54.

7 Chesterman CN, Chong BH, Shi W. Pathogenic potential of antiphospholipid antibodies: binding to human platelets. Thromb Haemost 1991;65:555A.

8 del Papa N, Meroni PL, Barcellini W, Borghi MO, Fain C, Khamashta $\mathrm{M}$, et al. Antiphospholipid antibodies crossreacting with erythrocyte membranes. A case report. Clin reacting with erythrocyte memb

9 Cuadrado MJ, Mujic F, Muñoz E, Khamashta MA, Hughes GR. Thrombocytopenia in the antiphospholipid syndrome. GR. Thrombocytopenia in the an

10 Stasi R, Stipa E, Masi M, Cecconi M, Scimo MT, Oliva F, et al. Long-term observation of 208 adults with chronic idiopathic thrombocytopenic purpura. Am J Med 1995;98. $436-42$.
11 Julià A, Araguas C, Rosselló J, Bueno J, Domenech P, Olona $\mathrm{M}$, et al. Lack of useful clinical predictors of response to splenectomy in patients with chronic immune thrombocytopenic purpura. Br J Haematol 1990;76:250-2.

12 Cervera R, Font J, Lopez-Soto A, Casals F, Pallares L, Bove A, et al. Isotype distribution of anticardiolipin antibodies in systemic lupus erythematosus: prospective analysis of a series of 100 patients. Ann Rheum Dis 1990;49:109-13.

13 Font J, Cervera R, Lopez-Soto A, Pallarés L, Bosch X, Ampurdanés S, et al. Anticardiolipin antibodies in patients with autoimmune diseases: isotype distribution and clinical associations. Clin Rheumatol 1989;8:475-83.

14 Guzman J, Cabral AR, Cabiedes J, Pita-Ramírez L, Alarcón-Segovia D. Antiphospholipid antibodies in patients with idiopathic autoimmune haemolytic anemia. Autoimmunity 1994;18:51-6.

15 Cervera R, Khamashta MA, Font J, Sebastiani GD, Gil A, Lavilla $\mathrm{P}$, et al. Morbidity and mortality in systemic lupus erythematosus during a 5-year period: a multicenter prospective study of 1000 patients. Medicine (Baltimore) 1999;78:167-75.

16 Pallarés JA, Caba F. Anesthesic implications of antiphospholipid syndrome. Two cases report. Rev Esp Anestesiol Reanim 1995;42:182-5.

17 Leuzzi RA, Davis GH, Cowchock FS, Murphy S, Vernick JJ. Management of immune thrombocytopenic purpura associated with the antiphospholipid antibody syndrome. Clin Exp Rheumatol 1997;15:197-200.

18 Ballerini G, Gemmati D, Moratelli S, Morelli P, Serino ML. Anticardiolipin antibody-related thrombocytopenia: persistent remission after splenectomy. Haematologica 1995; 80:248-51.

19 Hakim AJ, Machin SJ, Isenberg DA. Autoimmune thrombocytopenia in primary antiphospholipid syndrome and systemic lupus erythematosus: the response to splenectomy. Semin Arthritis Rheum 1998;28:20-5.

20 Galindo M, Khamashta MA, Hughes GRV. Splenectomy for refractory thrombocytopenia in the antiphospholipid syndrome. Rheumatology 1999;38:848-53. 